Article

\title{
Determination of Tryptophan and Its Major Metabolites in Fluid from the Anterior Chamber of the Eye in Diabetic Patients with Cataract by Liquid Chromotography Mass Spectrometry (LC-MS/MS)
}

\author{
Jolanta Flieger ${ }^{1, *(D)}$, Anna Święch-Zubilewicz ${ }^{2}$, Tomasz Śniegocki ${ }^{3}$, Joanna Dolar-Szczasny ${ }^{2}$ (D) \\ and Magdalena Pizoń ${ }^{1}$ \\ 1 Department of Analytical Chemistry, Medical University of Lublin, Chodźki 4A, 20-093 Lublin, Poland; \\ magdalenapizon@umlub.pl \\ 2 Department of Retinal and Vitreal Surgery, Medical University of Lublin, Chmielna 1, 20-079 Lublin, Poland; \\ annazub@umlub.pl (A.Ś-Z.); joannaszczasny@op.pl (J.D.-S.) \\ 3 Department of Pharmacology and Toxicology, National Veterinary Research Institute, 24-100 Pulawy, \\ Poland; sniego@piwet.pulawy.pl \\ * Correspondence: j.flieger@umlub.pl; Tel.: +48-81448-7194; Fax: +48-81535-7350 \\ Academic Editor: Makoto Tsunoda \\ Received: 22 October 2018; Accepted: 15 November 2018; Published: 17 November 2018

\begin{abstract}
Tryptophan (TRP) is to an essential amino acid and its catabolites are significant to human health. By using ultra-high-performance liquid chromatography coupled to electrospray ionization triple quadrupole mass spectrometry (UHPLC-ESI-MS/MS), levels of three major components of kynurenic pathway namely tryptophan (TRP), kynurenic acid (KYNA) and kynurenine (KYN) in fluid from the anterior chamber of the eye were determined. The analysis was carried out on a Synergi $4 \mu$ Fusion-RP column using gradient elution mode. For quantitative determination, L-tryptophan-amino-15N, 99 ATOM \% 15N was used as an internal standard. The method was linear in the concentration range $4-2000 \mathrm{ng} \mathrm{mL}^{-1}$ for TRP, KYNA and KYN. The mean recoveries measured at four concentration levels for TRP, KYN and KYNA included the following ranges 94.3-96.1; 91.0-95.0; and 96.0-97.6\%, respectively. The intra-day precision parameters were smaller than 4.4, 6.4 and 5\% respectively. The developed method was applied to study the level of TRP, KYNA and KYN in eye fluid for the retrospective case series which included 28 patients suffering from cataracts and diabetes $(n=8)$. The experimental data was subjected to statistical analysis. The Mann-Whitney U-test revealed clear differences in the level of TRP catabolites and the ratios of TRP/KYN representing the activities of specific enzyme of kynurenine pathway in examined groups of patients. A level of probability $p<0.05$ was used throughout a paper to denote statistically significant differences between the groups.
\end{abstract}

Keywords: chromatography; tryptophan metabolites; kynurenine pathway; cataracts; diabetes

\section{Introduction}

The main route of tryptophan (TRP) degradation is through kynurenine pathway (KP) accounting for $\sim 95 \%$ of its overall degradation. The KP leads to production of metabolites, such as kynurenic acid (KYNA), kynurenine (KYN), anthranilic acid (AA), 3-OH kynurenine (3-OH KYN), xanthurenic acid (XA), 3-hydroxybutyrate anthranilic acid (3-HAA), quinolinic acid (QA) subsequently denoted as kynurenines and, finally, to biosynthesis of a crucial cofactor, namely, nicotinamide adenine dinucleotide (NAD+) [1]. The process of metabolizing TRP into KYN takes place in different locations mostly in the liver, kidneys and the brain with the help of three enzymes: TRP-2,3-dioxygenase, 
indoleamine-2,3-dioxygenase-1 and indoleamine dioxygenase-2 [1,2]. It should be emphasized that humans are not able to synthesize TRP by themselves, therefore, it comes only from the diet. In recent years, many researches have proven a significant role of the KP in the pathogenesis of several serious disorders, such as cancer, psychiatric, neurodegenerative and autoimmune system dysfunctions [3]. The examination of TRP metabolites levels has been studied in brain tissue and amniotic fluid [4], serum [5,6] cerebrospinal fluid [7], human cataracts' lenses [8] and saliva of a diabetic patient [9]. There is also evidence that the KP pathway is connected with visual function as KYN and 3-OH-KYN glycoside derivatives act as UV filters and protect the retina and the lens by absorbing the UV radiation [8,10-14]. On the other hand, the kynurenine pathway-derivatives were identified as compounds inducing that is, cataract formation $[8,10,14]$. Till now determination of TRP catabolites has been developed by a sensitive, rapid and specific high-performance liquid chromatography coupled to tandem mass spectrometry, however, ultra-violet or fluorescent absorbance and electrochemical detectors can be also applied for this purpose [15-25].

The goal of this study was to quantify of tryptophan and its major metabolites, kynurenine and kynurenic acid by LC-MS/MS using L-tryptophan-amino-15N, 99 ATOM \% 15N as an internal standard. The elaborated method was assessed for validation parameters. Feasibility of the method was demonstrated in fluid from the anterior chamber of the eye in patients. Patients were divided into those with cataracts and compared to patients with coexisting diabetes. To test differences between the groups, the experimental results have been analysed by a statistical method. The levels of TRP, KYN, KYNA, the ratios of catabolites to each other were considered as the factors. Additionally, the age of patients was considered as an independent variable.

\section{Results and Discussion}

LC/MS/MS as an essential method to identify and quantify TRP and its kynurenine metabolites was applied to the present study. Our procedure was based on a simple "dilute-and-shoot" liquid chromatography-tandem mass spectrometry (LC-MS/MS) method which was previously used for the simultaneous quantitation of drugs of abuse, in biological samples for forensic toxicology purposes [26,27]. UHPLC ensured and improved either throughput and sensitivity of the method.

The elaborated conditions ensured successful separation of examined analytes within 2 min (Figure 1).

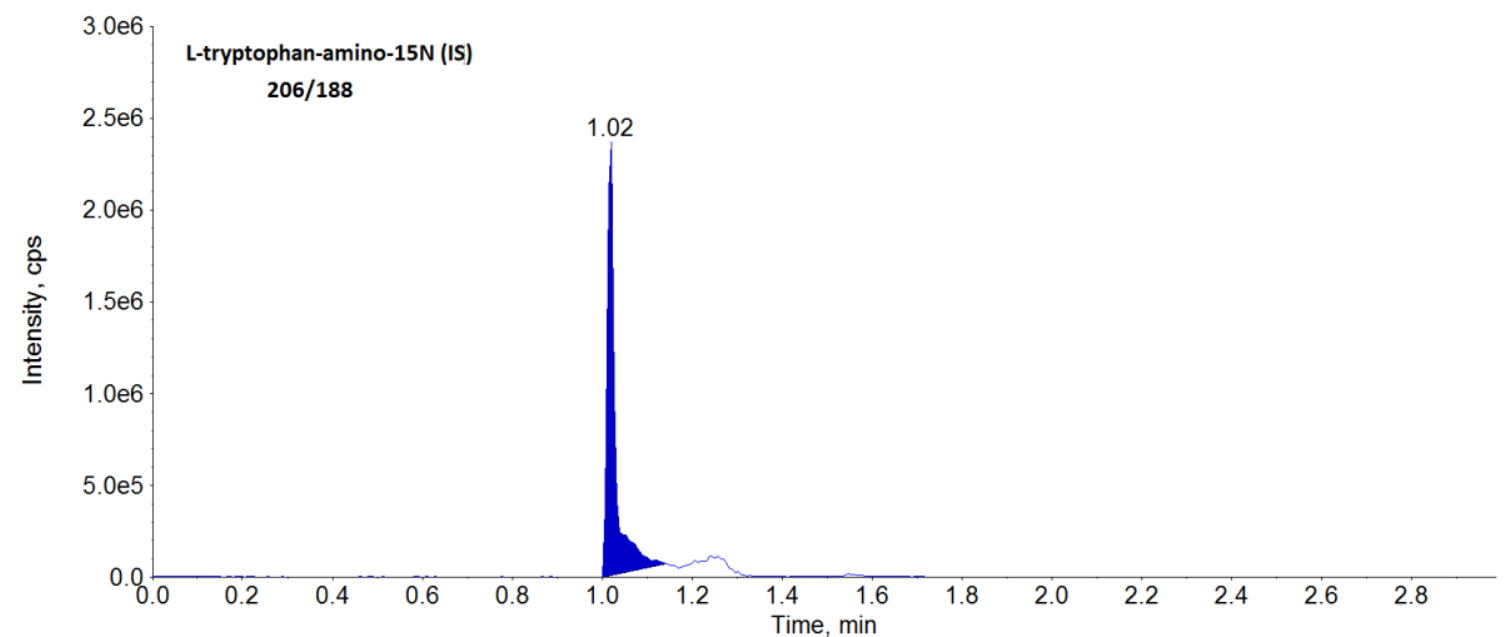

(A)

Figure 1. Cont. 


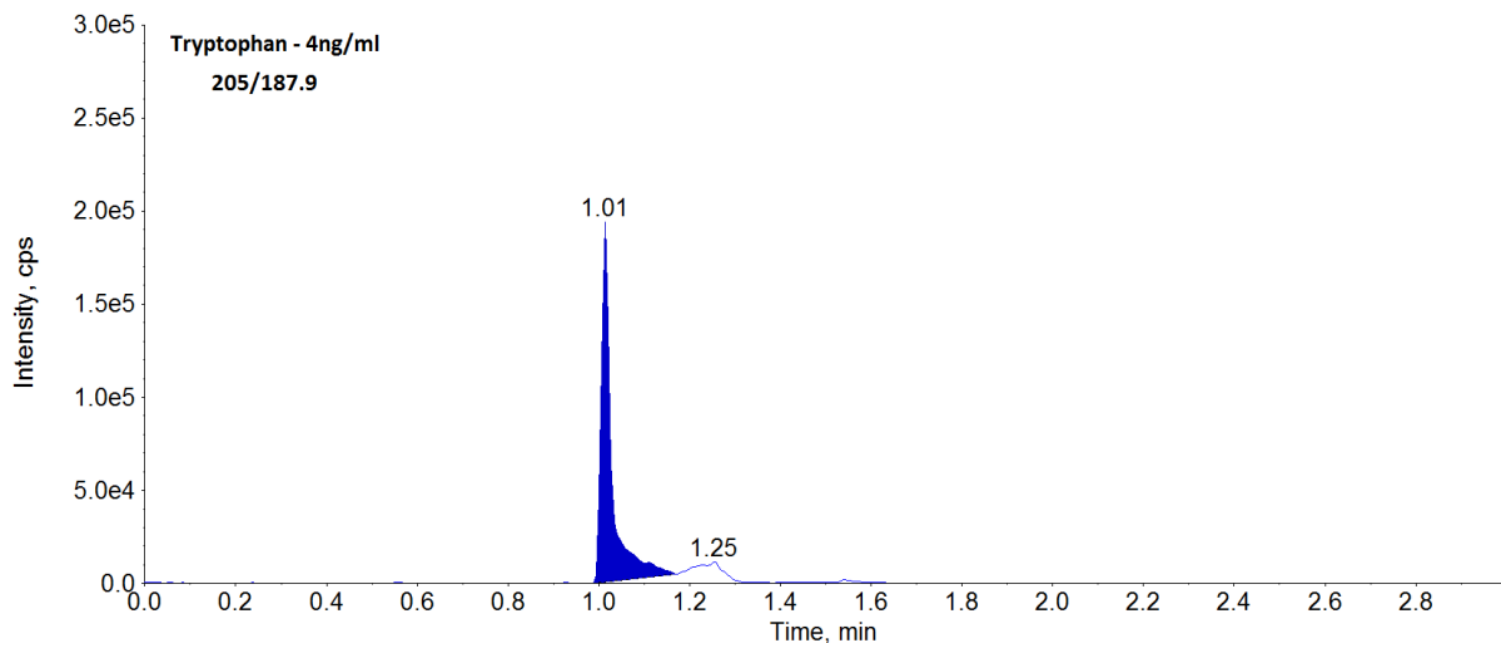

(B)

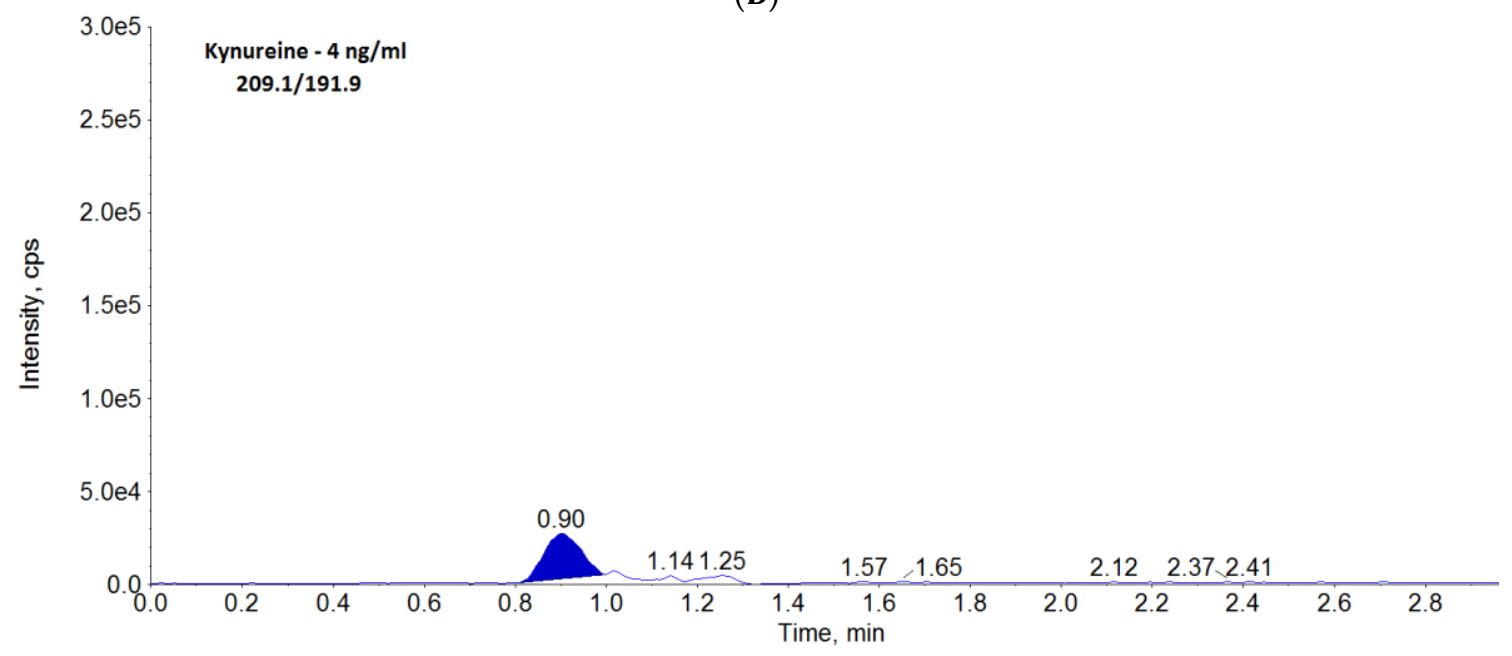

(C)

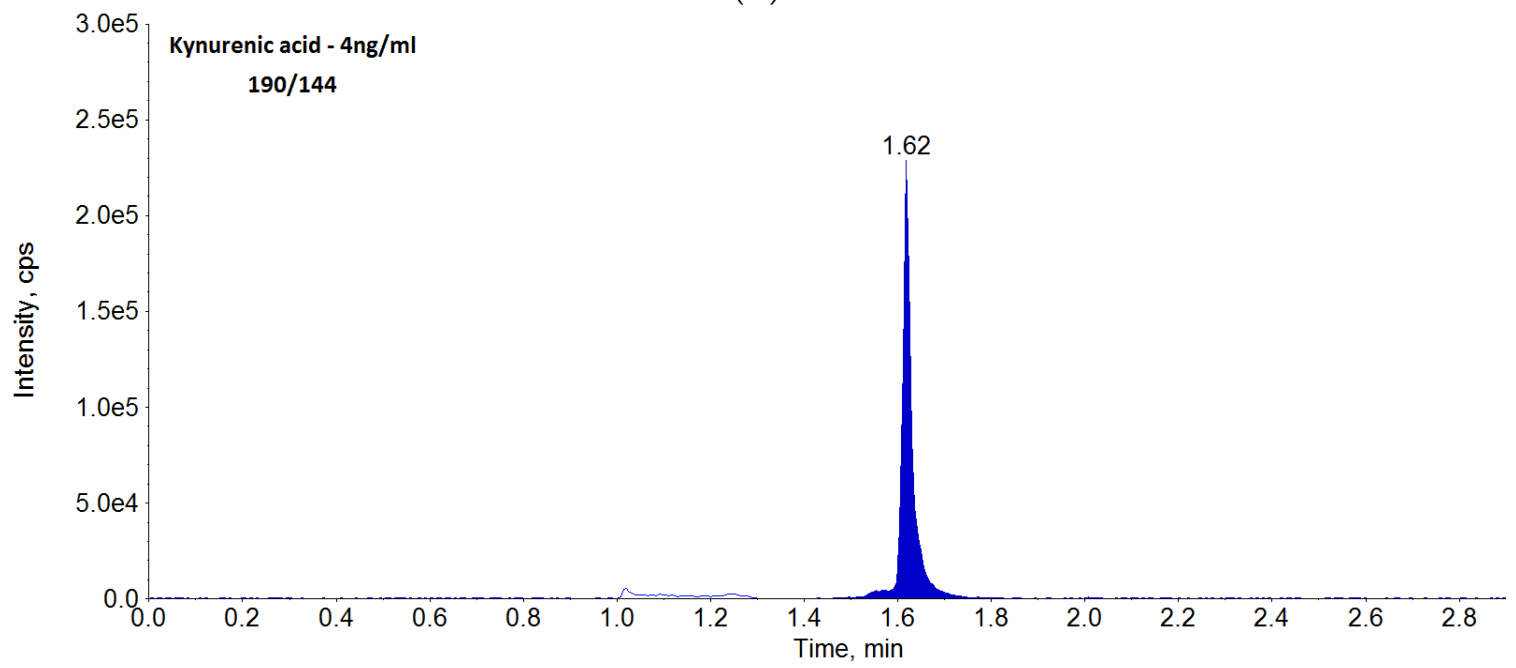

(D)

Figure 1. Chromatograms obtained from analysis of standards of IS (A), tryptophan (B), kynurenine (C), kynurenic acid (D) by LC-MS/MS.

Proposed procedure was subjected to a number of validation criteria as, so far, there is no studies describing analysis of TRP metabolites in the fluid from the anterior chamber of the eye. A linear response of the peak area was observed over a concentration range of $4-2000 \mathrm{ng} \mathrm{mL}^{-1}$. It should 
be emphasized that such a wide range of the calibration curve from 4-2000 is acceptable for API instrument $[28,29]$. The correlation coefficient values obtained from plotting the peak area against the nominal concentration were higher than 0.99 at each case. Linearity was observed for each concentration range between this at the LOD and the highest concentrations tested. The parameters of the linear regression function are collected in Table 1.

Table 1. Parameters obtained for the calibration curve.

\begin{tabular}{cccc}
\hline Analyte & $\begin{array}{c}\text { Concentration Range } \\
(\mathbf{n g} / \mathbf{m L})\end{array}$ & Determination Coefficient & Calibration Curve \\
\hline Tryptophan & $4-2000$ & 0.9973 & $\mathrm{y}=0.0213( \pm 0.0015) \mathrm{x}-0.0330( \pm 0.0023)$ \\
Kynurenine & $4-2000$ & 0.9972 & $\mathrm{y}=0.0325( \pm 0.0030) \mathrm{x}-0.0325( \pm 0.0030)$ \\
Kynurenic acid & $4-2000$ & 0.9982 & $\mathrm{y}=0.0088( \pm 0.0010) \mathrm{x}-0.1097( \pm 0.0121)$ \\
\hline
\end{tabular}

LOD and LOQ were calculated as the analyte concentrations which give rise to peaks 3 and 10 times higher than the baseline noise, respectively, varied between 0.2 and $1.20 \mathrm{ng} / \mathrm{mL}$ for LOD and 0.66 and $3.9 \mathrm{ng} / \mathrm{mL}$ for LOQ (Table 2).

Table 2. LOQ and LOD values.

\begin{tabular}{cccc}
\hline Analyte & Tryptophan & Kynurenine & Kynurenic Acid \\
\hline LOD $(\mathrm{ng} / \mathrm{mL})$ & 0.20 & 1.20 & 0.40 \\
LOQ $(\mathrm{ng} / \mathrm{mL})$ & 0.66 & 3.9 & 1.32 \\
\hline
\end{tabular}

The relative recoveries were estimated by measuring spiked samples of TRP, KYN, KYNA at four concentrations with 3 replicates of each. No statistically significant differences were noticed for the lower and higher concentrations as shown in Table 3. Because the fluid from the anterior chamber of the eye without tryptophan and its metabolites does not exist, purified water was used as a matrix. As shown, recoveries of TRP, KYN and KYNA varied between 94.3-96.1\%, 91-95\% and 96-97.6\% respectively.

Table 3. Validation parameters.

\begin{tabular}{lcccc}
\hline Parameters & \multicolumn{4}{c}{ Tryptophan } \\
\hline Fortification level (ng/mL) & 50 & 150 & 400 & 2000 \\
Average recovery $(n=18)(\%)$ & $95.0 \pm 3.2$ & $96.1 \pm 3.4$ & $98.0 \pm 4.0$ & $94.3 \pm 2.2$ \\
Average repeatability, (RSDr, \%) & $4.4 \pm 3.4$ & $3.4 \pm 2.2$ & $3.6 \pm 3.9$ & $4.1 \pm 4.1$ \\
Average within-lab reproducibility, (RSDwR, \%) & $5.7 \pm 3.2$ & $5.0 \pm 3.0$ & $5.2 \pm 2.0$ & $5.4 \pm 3.8$ \\
\hline & \multicolumn{4}{c}{ Kynurenine } \\
\hline Fortification level (ng/mL) & 10 & 50 & 150 & 400 \\
Average recovery ( $n=18)(\%)$ & $91.0 \pm 4.6$ & $92.2 \pm 4.2$ & $94.6 \pm 3.0$ & $95.0 \pm 4.3$ \\
Average repeatability, (RSDr, \%) & $5.5 \pm 3.9$ & $4.9 \pm 4.4$ & $5.1 \pm 4.3$ & $6.4 \pm 4.1$ \\
Average within-lab reproducibility, (RSDwR, \%) & $6.9 \pm 5.3$ & $5.1 \pm 4.3$ & $4.8 \pm 4.5$ & $5.8 \pm 5.2$ \\
\hline & \multicolumn{4}{c}{ Kynurenic acid } \\
\hline Fortification level (ng/mL) & 4 & 10 & 50 & 150 \\
Average recovery ( $n=18)(\%)$ & $96.0 \pm 3.7$ & $96.3 \pm 3.5$ & $97.2 \pm 3.8$ & $97.6 \pm 2.6$ \\
Average repeatability, (RSDr, \%) & $5.0 \pm 3.6$ & $3.6 \pm 2.9$ & $3.2 \pm 3.4$ & $4.0 \pm 3.7$ \\
Average within-lab reproducibility, (RSDwR, \%) & $5.3 \pm 3.9$ & $4.2 \pm 3.3$ & $4.4 \pm 2.9$ & $4.6 \pm 3.2$ \\
\hline
\end{tabular}

The method provided satisfactory precision expressed by relative standard deviation values. Precision values expressed as RSD\% values were lower than 5\% for repeatability (intra-day precision) and lower than $7 \%$ for intermediate precision (reproducibility, inter-day precision).

The results in Table 4 show content of the kynurenine metabolites determined in aqueous humour of 28 subjects who underwent cataract extraction surgery. All clinical samples have been divided into 
two groups: the first group including patients with cataract and the second one with cataract with coexisting diabetes.

Table 4. The level of TRP, KYNA and KYN [ng/mL] and metabolites ratios determined in eye fluid for the retrospective case series of 28 patients suffered from cataracts including 8 patients with coexisting diabetes.

\begin{tabular}{|c|c|c|c|c|}
\hline & \multicolumn{4}{|c|}{ Diabetes and Cataract $(n=8)$} \\
\hline & Range & Mean \pm Standard Deviation & Median & $\mathrm{CV}$ \\
\hline $\mathrm{KYN}(\mathrm{ng} / \mathrm{mL})$ & 21.85-191.84 & $64.06 \pm 56.17$ & 41.93 & 0.876 \\
\hline KYNA (ng/mL) & $6.22-8.51$ & $6.94 \pm 0.72$ & 6.78 & 0.104 \\
\hline $\mathrm{TRP}(\mathrm{ng} / \mathrm{mL})$ & $694.86-1784.12$ & $1010.69 \pm 387.45$ & 817.76 & 0.383 \\
\hline TRP/KYNA & $101.57-256.80$ & $145.53 \pm 53.36$ & 125.81 & 0.367 \\
\hline TRP/KYN & $9.33-33.46$ & $20.59 \pm 8.72$ & 19.23 & 0.423 \\
\hline \multirow[t]{3}{*}{ KYN/KYNA } & $3.40-27.54$ & $9.29 \pm 8.12$ & 6.51 & 0.874 \\
\hline & \multicolumn{4}{|c|}{ Cataract $(n=20)$} \\
\hline & Range & Mean \pm Standard Deviation & Median & $\mathrm{CV}$ \\
\hline $\mathrm{KYN}(\mathrm{ng} / \mathrm{mL})$ & $16.61-67.84$ & $31.11 \pm 14.59$ & 27.37 & 0.469 \\
\hline KYNA (ng/mL) & $5.83-6.76$ & $6.19 \pm 0.23$ & 6.17 & 0.038 \\
\hline $\mathrm{TRP}$ (ng/mL) & $465.36-1356.26$ & $855.57 \pm 203.13$ & 835.02 & 0.237 \\
\hline TRP/KYNA & $75.72-219.30$ & $138.03 \pm 31.00$ & 132.25 & 0.225 \\
\hline TRP/KYN & $6.86-53.91$ & $32.12 \pm 11.72$ & 32.36 & 0.365 \\
\hline KYN/KYNA & $2.71-11.03$ & $5.01 \pm 2.29$ & 4.42 & 0.457 \\
\hline
\end{tabular}

Data was presented as mean \pm standard deviation and was all tested for homogeneity of variance by the Bartlett test at first. It appeared that obtained data did not follow the normal distribution. To compare two independent data coming from distinct populations, which can not affect each other, namely, "cataract group" and "diabetes group", the Manna-Whitney-U test corrected for ties has been applied (Table 5). Besides the content of metabolites, data expressing the following ratios TRP/KYNA, TRP/KYN, KYN/KYNA, has been added as an additional variable. Obtained values of $p$ indicate existence of the significant differences between "cataract group" and "diabetes group" regarding the level of KYN, KYNA and the ratio of TRP/KYN (Table 5, Figure 2). We did not find any correlations between remaining estimated parameters.

Table 5. The Manna-Whitney-U test corrected for ties. Marked tests are significant at $p<0.05000$.

\begin{tabular}{lcccccccc}
\hline Variables & $\begin{array}{c}\text { The Sum of a } \\
\text { Rank for } \\
\text { Diabetics Group }\end{array}$ & $\begin{array}{c}\text { The Sum of a } \\
\text { Rank for } \\
\text { Cataract Group }\end{array}$ & $\mathbf{U}$ & $\mathbf{Z}$ & $\boldsymbol{p}$ & $\begin{array}{c}\mathbf{Z} \text { (Corrected } \\
\text { for Ties) }\end{array}$ & $\mathbf{P}$ & $\mathbf{2 * 1} \mathbf{P}$ \\
\hline KYNA & 185.00 & 221.00 & 11.00 & 3.4836 & 0.0005 & 3.4836 & 0.0005 & 0.0001 \\
KYN & 161.00 & 245.00 & 35.00 & 2.2630 & 0.0236 & 2.2630 & 0.0236 & 0.0213 \\
TRP & 120.00 & 286.00 & 76.00 & 0.1780 & 0.8587 & 0.1780 & 0.8587 & 0.8617 \\
TRP/KYNA & 108.00 & 298.00 & 72.00 & -0.3814 & 0.7029 & -0.3814 & 0.7029 & 0.7086 \\
TRP/KYN & 71.00 & 335.00 & 35.00 & -2.2630 & 0.0236 & -2.2630 & 0.0236 & 0.0213 \\
KYN/KYNA & 150.00 & 256.00 & 46.00 & 1.7036 & 0.0885 & 1.7036 & 0.0885 & 0.0887 \\
$\begin{array}{l}\text { Age of } \\
\text { patient }\end{array}$ & 83.00 & 323.00 & 47.000 & -1.6528 & 0.0984 & -1.6562 & 0.0977 & 0.0991 \\
\hline
\end{tabular}

U-the values of the Mann-Whitney test when the group size is less than 20, Z-Mann Whitney test value when the group size is greater than 20, $p$-probability value for the test for value of the test statistics $Z, Z$-test statistic $Z$ (corrected for ties), $\mathrm{P}$ - probability value for test statistic $Z$ (corrected for ties), ${ }^{*} 1 \mathrm{P}$ - probability value when the group size is less than 20 . 


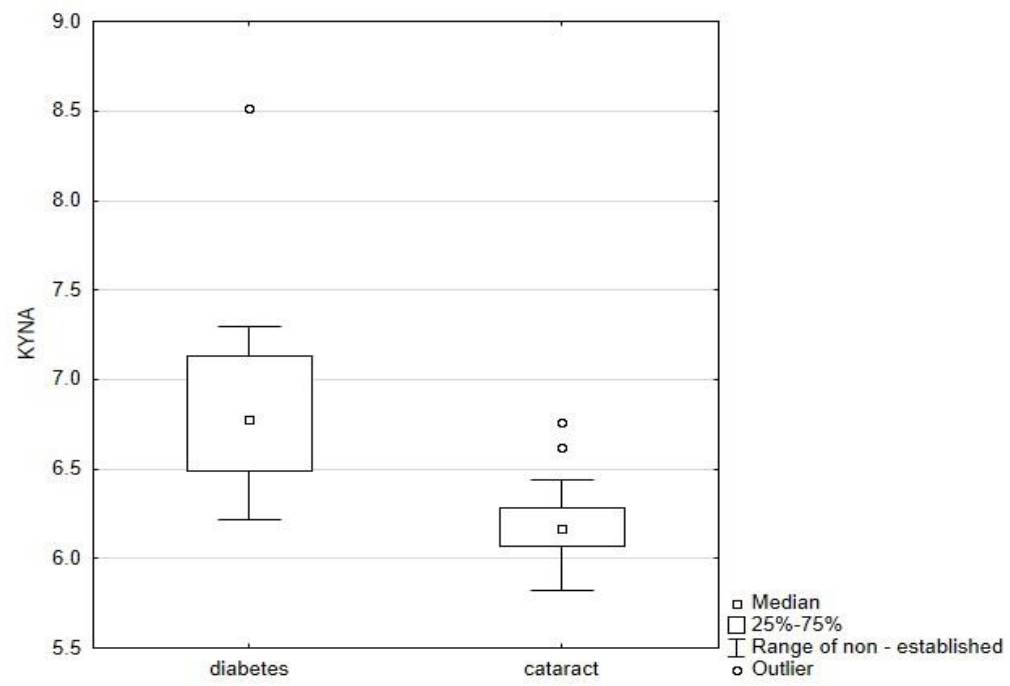

(A)

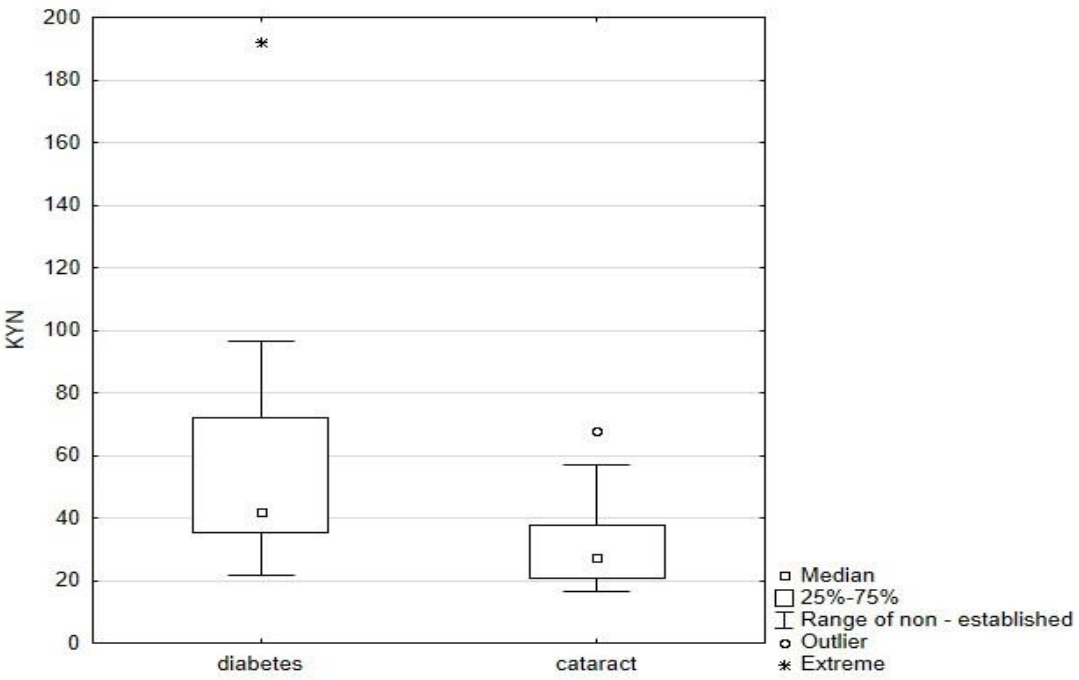

(B)

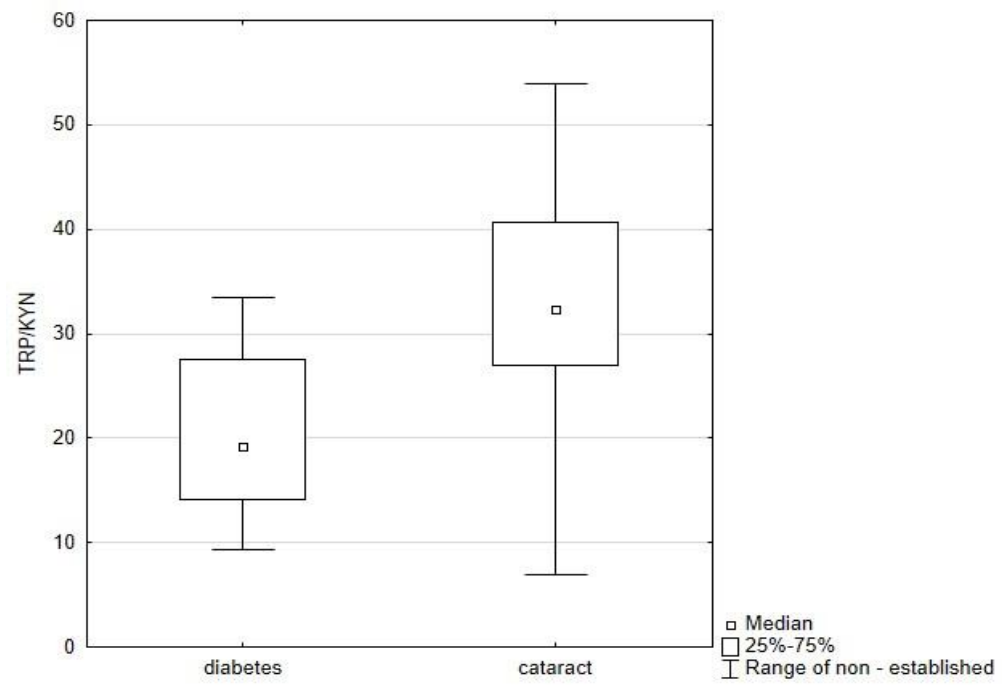

(C)

Figure 2. The box-plots representing statistically significant differences between the levels of KYNA (A), KYN (B) and ratio TRP/KYN (C) in patients with both studied groups. 
The concentrations of KYN and KYNA were significantly higher in patients with diabetes in comparison to cataracts alone. There were no differences in concentration of TRP and other metabolites ratios between the studied groups. The increased concentrations of KYN and KYNA in patients with diabetes suggest an altered metabolism of TRP.

\section{Materials and Methods}

\subsection{Sample Collection}

Performed experiments were done in agreement obtained by the Bioethics Commission of the Medical University of Lublin. Twenty-eight samples of fluid from the anterior chamber of the eye were collected at the beginning of cataract extraction surgery. The samples were stored in $1.5 \mathrm{~mL}$ polypropylene tubes at $-80^{\circ} \mathrm{C}$ until analysis.

\subsection{Sample Preparation}

The purification was based on Dilute and Shoot (D\&S) method. Briefly, $15 \mu \mathrm{L}$ of the fluid from the anterior chamber of the eye was diluted by $15 \mu \mathrm{L}$ of internal standards (L-tryptophan-amino- $15 \mathrm{~N}$ ) and $30 \mu \mathrm{L}$ of $0.1 \%$ formic acid in water. Then, $10 \mu \mathrm{L}$ was injected into LC-MS/MS.

\section{3. $L C-M S / M S$}

The UHPLC-MS/MS system consisting of an AB Sciex ExionLC UHPLC system connected to an AB Sciex API 5500 Qtrap mass spectrometer (AB Sciex, Concord, ON, Canada). Analyst 1.6.3 software (AB Sciex) controlled the UHPLC-MS/MS system and Multiquant 3.2 (AB Sciex) was used to process the data. The mass spectrometer was operated in the positive ESI mode with a capillary voltage of $4.5 \mathrm{kV}$. The temperature of desolvation was set at $600{ }^{\circ} \mathrm{C}$, nebuliser gas $\left(\mathrm{N}_{2}\right)-40$; curtain gas $\left(\mathrm{N}_{2}\right)-40$; collision gas $\left(\mathrm{N}_{2}\right)$-medium; gas 1 (air)-35; gas 2 (air)-35. The multiplier was set at $2300 \mathrm{~V}$. The flow rate of mobile phase was $600 \mu \mathrm{L} \mathrm{min}{ }^{-1}$, the injection volume- $10 \mu \mathrm{L}$. The chromatography was performed on a Synergi $4 \mu$ Fusion-RP column $(50 \mathrm{~mm} \times 2 \mathrm{~mm} \times 4 \mu \mathrm{m})$, connected to a C18 precolumn $(4 \mathrm{~mm} \times 2 \mathrm{~mm} \times 4 \mu \mathrm{m})$. The mobile phase for LC analysis consisted of two solutions: A (0.1\% formic acid in water) and B (acetonitrile). The mobile phase gradient program started at $1 \%$ of $\mathrm{B}, 98 \% \mathrm{~B}$ at $0.55 \mathrm{~min}$ to $1 \mathrm{~min}$, then $1 \%$ of $\mathrm{B}$ at $1.1 \mathrm{~min}$ and held for $1.9 \mathrm{~min}$. The column was equilibrated for $2 \mathrm{~min}$. The column operated at $40{ }^{\circ} \mathrm{C}$ and the ions were monitored in Multiple Reaction Monitoring (MRM) mode (Table 6).

Table 6. Precursor ions and fragment ions of tryptophan, kynurenine, kynurenic acid and internal standards-mass spectrometry parameters.

\begin{tabular}{ccccccc}
\hline \multirow{2}{*}{ Analyte } & $\begin{array}{c}\text { Precursor } \\
\text { Ion }(\mathbf{m} / \mathbf{z})\end{array}$ & $\begin{array}{c}\text { Ion } \\
\text { Transition }\end{array}$ & $\begin{array}{c}\text { Declustering } \\
\text { Potential }\end{array}$ & $\begin{array}{c}\text { Collision } \\
\text { Energy (eV) }\end{array}$ & $\begin{array}{c}\text { Collision Cell } \\
\text { Exit Potential }\end{array}$ & $\begin{array}{c}\text { Entrance } \\
\text { Potential }\end{array}$ \\
\hline \multirow{2}{*}{ Tryptophan } & 205.0 & 188.0 & \multirow{2}{*}{50} & 16 & 16 & 10 \\
& 146.0 & & 23 & 10 & 10 \\
\hline \multirow{2}{*}{ Kynurenine } & \multirow{2}{*}{209.1} & 191.9 & \multirow{2}{*}{66} & 11 & 14 & 10 \\
\hline \multirow{2}{*}{ Kynurenic acid } & \multirow{2}{*}{190.0} & 146.0 & & 25 & 10 & 10 \\
\hline (IS) & 142.0 & \multirow{2}{*}{81} & 25 & 12 & 10 \\
\hline
\end{tabular}

\subsection{Validation}

The analytical-method validation was carried out according to the ICH Q2 (R1) method-validation guidelines [30] and others [31-33]. The following validation parameters were established: selectivity, linearity, precision, LOD and LOQ. The method validation was also based on other literature data, describing an analysis of endogenous compounds in a biological matrix [34,35]. 


\subsubsection{Calibration Solutions and Standards}

Analyte standard solutions at different concentrations: 4, 10, 50, 150, 400, $2000 \mathrm{ng} / \mathrm{mL}$ were added to the blank sample, subjected to the D\&S and HPLC procedure. The analyte peak area was plotted against the corresponding concentrations and the calibration curves were set up by means of the least-squares method.

\subsubsection{LOD and LOQ}

LOD and LOQ were estimated by calculations based on Signal-to-Noise ratio. Determination of the signal-to-noise ratio is performed by comparing measured signals from samples with known low concentrations of analyte with those of blank samples and establishing the minimum concentration at which the analyte can be reliably detected or quantified concentration at which the analyte can be reliably quantified. A typical signal-to-noise ratio is 3:1 for LOD and 10:1 LOQ.

\subsubsection{Precision}

Spiked blank samples were prepared as follows: $15 \mu \mathrm{L}$ of standard solution of different concentration were added to $15 \mu \mathrm{L}$ of the water and was diluted by $15 \mu \mathrm{L}$ of internal standards (L-tryptophan-amino- $15 \mathrm{~N}$ ) and $15 \mu \mathrm{L}$ of $0.1 \%$ formic acid in water. At least four concentrations were prepared and analysed for each compound, corresponding to the lower, two middle and upper limit of the respective linearity curve. Spiked blank samples were prepared and analysed according to the described procedure. The analysis was repeated twelve times giving intraday precision values and twelve times in another day giving intermediate precision values, both expressed as RSD\%.

\subsection{Statistical Analysis}

The statistical analysis was carried out in the STATISTICA versus 12 program using the Mann-Whitney U-test. The statistical significance level was assumed for $p$ values $<0.05$.

\section{Conclusions}

Examination of tryptophan metabolism can help to understand an aetiology as well as consequences of many diseases. Experiments on the fluid from the anterior chamber of the eye suggest that neuroactive metabolites of the tryptophan (TRP) in the kynurenine pathway (KP) may play a significant role in cataract formation in patients suffering from diabetes. The elevation of KYNA levels has been previously observed in cataractous lenses [8]. Our study has proven the increased content of KYN and KYNA and the ratio of TRP/KYN in the eye fluid of cataract patients suffering from diabetes. Obtained results, similarly to literature data, confirm that tryptophan metabolism is not only dysregulated during diabetes but also affects ophthalmological complications.

However, there is a need for further experiments in the aim to support the obtained results and fully explain the role of tryptophan metabolism in the pathogenesis of cataracts in diabetic patients.

Author Contributions: Conceptualization and writing J.F. and A.Ś.-Z.; Sample collection J.D.-S.; UHPLC/MS/MS analysis T.Ś.; Statistical analysis M.P.

Funding: This research received no external funding.

Conflicts of Interest: The authors declare no conflict of interest.

\section{References}

1. Palego, L.; Betti, L.; Rossi, A.; Giannaccini, G. Tryptophan Biochemistry: Structural, Nutritional, Metabolic, and Medical Aspects in Humans. J. Amino Acids 2016, 8952520. [CrossRef] [PubMed]

2. Badawy, A.A.-B. Kynurenine Pathway of Tryptophan Metabolism: Regulatory and Functional Aspects. Int. J. Tryptophan Res. 2017, 10, 1-12. [CrossRef] [PubMed] 
3. Chen, Y.; Guillemin, G.J. Kynurenine pathway metabolites in humans: Diseaseand healthy states. Int. J. Tryptophan Res. 2009, 2, 1-19. [CrossRef] [PubMed]

4. Stone, T.W. Kynurenines in the CNS: From endogenous obscurity to therapeutic importance. Prog. Neurobiol. 2001, 64, 185-218. [CrossRef]

5. Lesniak, W.G.; Jyoti, A.; Mishra, M.K.; Louissaint, N.; Romero, R.; Chugani, D.C.; Kannan, S.; Kannan, R.M. Concurrent quantification of tryptophan and its major metabolites. Anal. Biochem. 2013, 443, 222-231. [CrossRef] [PubMed]

6. Vignau, J.; Jacquemont, M.C.; Lefort, A.; Imbenotte, M.; Lhermitte, M. Simultaneous determination of tryptophan and kynurenine in serum by HPLC with UV and fluorescence detection. Biomed. Chromatogr. 2004, 18, 872-874. [CrossRef] [PubMed]

7. Bao, Y.; Luchetti, D.; Schaeffer, E.; Cutrone, J. Determination of kynurenic acid in rat cerebrospinal fluid by HPLC with fluorescence detection. Biomed. Chromatogr. 2016, 30, 62-67. [CrossRef] [PubMed]

8. Żarnowski, T.; Rejdak, R.; Zielińska-Rzecka, E.; Zrenner, E.; Grieb, P.; Zagórski, Z.; Junemann, A.; Turski, W.A. Elevated concentrations of kynurenic acid, a tryptophan derivative in dense nuclear cataracts. Curr. Eye Res. 2007, 32, 27-32. [CrossRef] [PubMed]

9. Buczko, P.; Stokowska, W.; Górska, M.; Kucharewicz, I.; Pawlak, D.; Buczko, W. Tryptophan metabolites via kynurenine pathway in saliva of diabetic patients. Dent. Med. Probl. 2006, 43, 21-25.

10. Matysik-Woźniak, A.; Jünemann, A.; Turski, W.A.; Wnorowski, A.; Jóźwiak, K.; Paduch, R.; Okuno, E.; Moneta-Wielgoś, J.; Choragiewicz, T.; Maciejewski, R.; et al. The presence of kynurenine aminotransferases in the human cornea: Evidence from bioinformatics analysis of gene expression and immunohistochemical staining. Mol. Vis. 2017, 23, 364-371. [PubMed]

11. Rejdak, R.; Oleszczuk, A.; Rummelt, C.; Turski, W.A.; Choragiewicz, T.; Nowomiejska, K.; Ksiazek, K.; Thaler, S.; Zarnowski, T.; Okuno, E.; et al. Presence and distribution of 1-kynurenine aminotransferases immunoreactivity in human cataractous lenses. Acta Ophtalmol. 2013, 91, e450-e455. [CrossRef] [PubMed]

12. Wood, A.M.; Truscott, R.J.W. UV filters in human lenses: Tryptophan catabolism. Exp Eye Res. 1993, 56, 317-325. [CrossRef] [PubMed]

13. Tsentalovich, Y.P.; Sherin, P.S.; Kopylova, L.V.; Cherepanov, I.V.; Grilj, J.; Vauthey, E. Photochemical properties of UV filter molecules of the human eye. Investig. Ophthalmol. Vis. Sci. 2011, 52, 7687-7696. [CrossRef] [PubMed]

14. Mailankot, M.; Staniszewska, M.M.; Butler, H.; Caprara, M.H.; Howell, S.; Wang, B.; Doller, C.; Reneker, L.W.; Nagaraj, R.H. Indoleamine 2,3-dioxygenase overexpression causes kynurenine-modification of proteins, fiber cell apoptosis and cataract formation in themouse lens. Lab. Investig. 2009, 89, 498-512. [CrossRef] [PubMed]

15. Mitsuhashi, S.; Fukushima, T.; Tomiya, M.; Santa, T.; Imai, K.; Toyo'oka, T. Determination of kynurenine levels in rat plasma by high-performance liquid chromatography with pre-column fluorescence derivatization. Anal. Chim. Acta 2007, 584, 315-321. [CrossRef] [PubMed]

16. Xiao, L.D.; Luo, X.B.; Pi, L.G.; Tang, A.G. Simultaneous determination of kynurenine and kynurenic acid concentrations in human serum by with dual wavelengths fluorescence detection. Clin. Chim. Acta 2008, 395, 178-180. [CrossRef] [PubMed]

17. Pi, L.G.; Tang, A.G.; Mo, X.M.; Luo, X.B.; Ao, X. More rapid and sensitive method for simultaneous determination of tryptophan and kynurenic acid by HPLC. Clin. Biochem. 2009, 42, 420-425. [PubMed]

18. Zagajewski, J.; Drozdowicz, D.; Brzozowska, I.; Hubalewska-Mazgaj, M.; Stelmaszynska, T.; Laidler, P.M.; Brzozowski, T. Conversion L-tryptophan to melatonin in the gastrointestinal tract: The new high performance liquid chromatography method enabling simultaneous determination of six metabolites of L-tryptophan by native fluorescence and UV-VIS detection. J. Physiol. Pharmacol. 2012, 63, 613-621. [PubMed]

19. Chen, G.-Y.; Zhong, W.; Zhou, Z.; Zhang, Q. Simultaneous determination of tryptophan and its 31 catabolites in mouse tissues by polarity switching UHPLC-SRM-MS. Anal. Chim. Acta 2018, 1037, 200-210. [CrossRef] [PubMed]

20. De Jong, W.H.; Smit, R.; Bakker, S.J.; de Vries, E.G.; Kema, I.P. Plasma tryptophan, kynurenine and 3-hydroxykynurenine measurement using automated on-line solid-phase extraction HPLC-tandem mass spectrometry. J. Chromatogr. B Anal. Technol. Biomed. Life Sci. 2009, 877, 603-609. [CrossRef] [PubMed] 
21. Zhu, W.; Stevens, A.P.; Dettmer, K.; Gottfried, E.; Hoves, S.; Kreutz, M.; Holler, E.; Canelas, A.B.; Kema, I.; Oefner, P.J. Quantitative profiling of tryptophan metabolites in serum, urine, and cell culture supernatants by liquid chromatography-tandem mass spectrometry. Anal. Bioanal. Chem. 2011, 401, 3249-3261. [CrossRef] [PubMed]

22. Moller, M.; Du Preez, J.L.; Harvey, B.H. Development and validation of a single analytical method for the determination of tryptophan, and its kynurenine metabolites in rat plasma. J. Chromatogr. B Anal. Technol. Biomed. Life Sci. 2012, 898, 121-129. [CrossRef] [PubMed]

23. Huang, Y.; Louie, A.; Yang, Q.; Massenkoff, N.; Xu, C.; Hunt, P.W.; Gee, W. A simple LC-MS/MS method for determination of kynurenine and tryptophan concentrations in human plasma from HIV-infected patients. Bioanalysis 2013, 5, 1397-1407. [CrossRef] [PubMed]

24. Choi, J.M.; Park, W.S.; Song, K.Y.; Lee, H.J.; Jung, B.H. Development of simultaneous analysis of tryptophan metabolites in serum and gastric juice-An investigation towards establishing a biomarker test for gastric cancer diagnosis. Biomed. Chromatogr. 2016, 30, 1963-1974. [CrossRef] [PubMed]

25. Henykova, E.; Vranova, H.P.; Amakorova, P.; Pospisil, T.; Zukauskaite, A.; Vlckova, M.; Urbanek, L.; Novak, O.; Mares, J.; Kanovsky, P.; et al. Stable isotope dilution ultra-high performance liquid chromatography-tandem mass spectrometry quantitative profiling of tryptophan-related neuroactive substances in human serum and cerebrospinal fluid. J. Chromatogr. A 2016, 1437, 145-157. [CrossRef] [PubMed]

26. Arias, J.L.O.; Schneider, A.; Andrade, J.A.B.; Vieira, A.A.; Gehrke, V.R.; Camargo, E.R.; Caldas, S.S.; Primel, E.G. Evaluation of dilute-and-shoot and solid-phase extraction methods for the determination of S-metolachlor and metolachlor-OA in runoff water samples by liquid chromatography tandem mass spectrometry. Anal. Methods 2017, 9, 5777-5783. [CrossRef]

27. He, X.; Kozak, M. Simultaneous Quantitation of 43 Drugs in Human Urine with a "Dilute-and-Shoot" LC-MS/MS Method; Application Note 576; Thermo Fisher Scientific: San Jose, CA, USA, 2012.

28. Bie, M.; Li, R.; Chai, T.; Dai, S.; Zhao, H.; Yang, S.; Qiu, J. Simultaneous Determination of Tetracycline Antibiotics in Beehives by Liquid Chromatography-Triple Quadrupole Mass Spectrometry. Adv. Appl. Sci. Res. 2012, 3, 462-468.

29. Shah, J.V.; Shah, P.A.; Sanyal, M.; Shrivastav, P.S. Simultaneous quantification of amiloride and hydrochlorothiazide in human plasma by liquid chromatography-tandem mass spectrometry. J. Pharm. Anal. 2017, 7, 288-296. [CrossRef] [PubMed]

30. ICH. Q2(R1) Validation of Analytical Procedures: Text and Methodology; International Conference on Harmonization: Geneva, Switzerland, 2005.

31. Chan, C.C.; Lam, H.; Lee, Y.C.; Zhang, X.-M. Analytical Method Validation and Instrument Performance Verification; Wiley-Interscience: New York, NY, USA, 2004; ISBN 0-471-25953-5.

32. Konieczka, P.; Namieśnik, J. Quality Assurance and Quality Control in the Analytical Chemical Laboratory: A Practical Approach, 1st ed.; Analytical Chemistry Series; CRC Press, Taylor and Francis Group: Milton Park/Abingdon, UK, 2018.

33. Konieczka, P.; Namieśnik, J. Quality Assurance and Quality Control in the Analytical Chemical Laboratory: A Practical Approach, 2nd ed.; CRC Press: Boca Raton, FL, USA, 2018.

34. Jaya, T.; Razia, K.; Divya, V. A validated HPLC-UV method and optimization of sample preparation technique for norepinephrine and serotonin in mouse brain. Pharm. Biol. 2015, 53, 1539-1544.

35. Martínez-Ortega, A.; Herrera, A.; Salmerón-García, A.; Cabeza, J.; Cuadros-Rodríguez, L.; Navas, N. Study and $\mathrm{ICH}$ validation of a reverse-phase liquid chromatographic method for the quantification of the intact monoclonal antibody cetuximab. J. Pharm. Anal. 2016, 6, 117-124. [CrossRef] [PubMed]

Sample Availability: Samples of L-tryptophan-amino-15N, L-tryptophan, L-kynurenine and L-kynurenic acid are not available from the authors but it can be purchased from the manufacturer: Sigma-Aldrich (St. Louis, MO, USA). 